\title{
Monitoring Effects of Ethanol Spray on Cabernet franc and Merlot Grapes and Wine Volatiles Using Electronic Nose Systems
}

\author{
Bruce W. Zoecklein, ${ }^{1 *}$ Yamuna S. Devarajan, ${ }^{2}$ Kumar Mallikarjunan, ${ }^{3}$ \\ and Denise M. Gardner ${ }^{2,4}$
}

\begin{abstract}
The ability of two electronic nose systems (conducting polymer and surface acoustic wave-based) to differentiate volatiles of grapes and wines treated with an aqueous ethanol spray $(5 \% \mathrm{v} / \mathrm{v})$ at veraison was evaluated. Ethanol spray induced fruit ethylene production immediately posttreatment, which then declined progressively. The electronic nose evaluations of grape volatiles were compared with Cabernet franc and Merlot physicochemistry and with wine gas chromatographic and aroma sensory data. Canonical discriminant and principal component analysis found that both electronic nose systems and the physicochemical measures (Brix, TA, $\mathrm{pH}$, color intensity and hue, total phenols, glycosides, and berry weight) were able to discriminate between ethanol-treated and untreated grapes and wines for both cultivars. Grape physicochemical treatment differences were due mainly to variations in hue, phenolic-free glycosides, and total phenols. Aroma sensory evaluations using a consumer panel differentiated between ethanol treatments and controls for Merlot, but not for Cabernet franc wines.
\end{abstract}

Key words: electronic nose, volatiles, Merlot, Cabernet franc

Days from bloom to harvest may be an important fruit, and subsequent wine, quality parameter (Haselgrove et al. 2000, Smart 1985). Indeed, it is widely accepted that "hang time" impacts aroma, flavor, and color (Bergqvist et al. 2001, Haselgrove et al. 2000). Additionally, color stability is reportedly impacted by the rate of fruit maturation (Bergqvist et al. 2001).

Ethylene is a plant hormone whose production at the onset of ripening is required to attain maturity for most fruits (Barry and Giovannoni 2007), although grapes are believed to be nonclimacteric (Coombe and Hale 1973). With nonclimacteric fruit, there is neither a burst of endogenous ethylene production nor a consistent growth response to exogenous ethylene. In grapes, the level of endogenous ethylene is low (Shulman et al. 1985) and declines from bloom to ripening (Weaver and Singh 1978), but may increase at veraison, causing a rise in respiration. Ethylene levels have been observed to remain relatively low before and after veraison (Coombe and Hale 1973), suggesting that ethylene plays a minor role in the ripening of grapes.

The effects of exogenous applications of ethylene, or ethylene-generating growth regulators, on grapes depend on rate, timing, cultivar, and region (Chervin et al. 2004, Hale et al. 1970, Powers et al. 1980, Shulman et al. 1985, Weaver and

\footnotetext{
${ }^{1}$ Professor Emeritus, Enology-Grape Chemistry Group, ${ }^{2}$ Graduate Student, and ${ }^{3}$ Associate Professor, Biological Systems Engineering, Virginia Tech, Blacksburg, VA 24061; ${ }^{4}$ resently, Enology Extension Associate, Pennsylvania State University, University Park, PA 16802.

*Corresponding author (email: bzoeckle@vt.edu; fax: 540 231-9293)

Acknowledgments: Virginia Agricultural Council and Virginia Wine Board.

Manuscript submitted Jan 2011, revised Mar 2011, accepted Apr 2011

Copyright (C) 2011 by the American Society for Enology and Viticulture. All rights reserved.

doi: 10.5344/ajev.2011.11005
}

Pool 1971). In Shiraz, there was a delaying or hastening effect on ripening rate by ethylene and/or ethephon (2-chloroethylphosphonic acid, formerly a commercially available growthregulating compound), depending on pre- or postveraison application (Hale et al. 1970). In Carignane, there were no changes in ripening, but ethephon was effective in increasing color, but only if applied at the start of veraison, not before (Weaver and Pool 1971). It has been suggested that ethephon causes a stress response in grapes that stimulates ethylene production (Weaver and Pool 1971) and that it stimulates phenylalanine ammonia-lyase (PAL) activity (Roubelakis-Angelakis and Kliewer 1986), a key enzyme in anthocyanin production.

Aqueous ethanol sprays may act similarly to ethephon (El Kereamy et al. 2002). Ethanol has been shown to increase anthocyanin concentration in cranberries (Farag et al. 1992), while ethanol vapor has been reported to increase the ripening of tomatoes (Beaulieu and Saltveit 1997). Investigations have shown that ethanol applied to grapes can retard or hasten the ripening process, depending on the concentration and timing (Beaulieu and Saltveit 1997). Spraying aqueous ethanol at 8 to 13 weeks postbloom enhanced grape and wine anthocyanin concentration and decreased acidity (Chervin et al. 2001, El Kereamy et al. 2002). Aqueous ethanol sprayed at 8 to 13 weeks postbloom on Cabernet Sauvignon grape clusters increased the anthocyanin content in berry skins and in subsequent juice and wines (Chervin et al. 2001, 2004). The mode of action is thought to be either an increase in fruit ethylene concentration or a direct effect on anthocyanin biosynthesis (El Kereamy et al. 2002). Ethanol may stimulate production of UDP-glucose flavonoid 3-O-glucosyl transferase, a key enzyme for the glycosylation of anthocyanins (El Kereamy et al. 2002) and other secondary metabolites, including aroma and flavor compounds (Hosel 1981). 
A major challenge for the grape and wine industry is to replace time-consuming laboratory analyses with new applications that are fast, precise, and accurate. For example, the analysis of grape and wine volatiles currently represents a significant limitation. Conventional analyses are mostly conducted using gas chromatographic (GC), GC-mass spectrometry (GC-MS), and GC olfactory (GC/O) methods and involve expensive equipment, methods development, and time- and labor-intensive steps, including sample preparation.

Electronic nose (ENose) technology represents a possible alternative to volatile measurement, at least in some applications. These units are multisensor arrays designed to detect volatile compounds. Each sensor type has a greater or lesser affinity for a particular chemical class or group of compounds. The adsorption of volatiles on the sensor surface causes a physical or chemical change in the sensor, allowing a specific pattern or "smellprint" of the volatiles (Mallikarjunan 2005). Using chemometric techniques and multivariate statistical analysis, it is possible to distinguish among groups of samples and, depending on the type of ENose, identify individual sample components. ENose systems are so-named because their methods of operation are analogous to the way the human sense of smell operates, where multiple nerve cells in the olfactory epithelium provide responses so the brain can identify and characterize aromas. ENoses are classified based on sensor type, including conducting polymer (CP) and surface acoustic wave (SAW) systems.

Conducting polymer units consist of an array of polymer sensors which, upon exposure to chemical vapor, expand, causing a change in electrical resistance. Each sensor is comprised of a different conductive material such as polypyrrole, polythiophene, polyaniline, polyacetylene, and polyindole, with a range of properties to allow discrimination among different types of volatiles, although cross-selectivity can occur (Mallikarjunan 2005, Pinheiro et al. 2002). Sensor responses are stored as smellprints and compared with the present readings during identification (Cyrano Sciences Inc., manufacturer guidelines, 2000). Primary problems reported with the use of conducting polymer sensors for wines are the influence of ethanol (Ragazzo-Sanchez et al. 2006) and water vapor. However, several studies used an ethanol baseline with a conducting polymer ENose system to minimize the interference of ethanol with sensor readings and base discrimination primarily on wine aroma and flavor volatiles (Devarajan et al. 2011, Gardner et al. 2011, Santos et al. 2004).

Surface acoustic wave ENose systems perform like a fastacting GC, using a single uncoated sensor to analyze volatiles quantitatively. Samples are drawn into a trap, the trap is heated to vaporize the sample, and the vapor is passed through a column, where the volatile is identified and quantified (Electronic Sensor Technology, operation manual, 2001). Generally, the sensitivity of various ENose systems varies according to sensor and polymer type. Sensitivity is reported to be in the $\mu \mathrm{g} / \mathrm{L}$ to $\mathrm{ng} / \mathrm{L}$ range (Mallikarjunan 2005).

This study evaluated the effect of aqueous ethanol sprays at veraison on Merlot and Cabernet franc grapes and subsequent wines. Conducting polymer and surface acoustic wave- based electronic nose systems were used to monitor grape and wine volatiles.

\section{Materials and Methods}

Field design. The study used Cabernet franc and Merlot (Vitis vinifera L.) grapes, grown on a Ballerina training system in central Virginia during the 2008 growing season. Heat summation for the site was $1154.4^{\circ} \mathrm{C}$, average monthly rainfall from April through October was $81 \mathrm{~mm}$, and mean relative humidity in September was $75 \%$.

Clone 4 Cabernet franc was planted in 2003 on 101-14 rootstock, with grapevine canopy sides facing east/west $\left( \pm 5^{\circ}\right)$ in a $4040 \mathrm{~m}^{2}$ plot. Vines were spaced 2.13 x $3.05 \mathrm{~m}$ apart. Fruit from the Cabernet franc canopy sides was monitored separately, with Cabernet franc-1 designated as the east side and Cabernet franc-2 as the west side of the canopy. Clone FPS 3 Merlot vines, grafted on 3309C rootstock, were planted in 1998 in a $20,274.76 \mathrm{~m}^{2}$ plot with $2.13 \times 3.05 \mathrm{~m}$ spacing. Merlot fruit was not segregated based on canopy side. Both the Cabernet franc and Merlot vineyards were dry-farmed and hedged twice to 15 nodes per shoot.

Ethanol treatment at veraison was carried out on 12 randomly selected Cabernet franc vines from each canopy side and 12 Merlot vines; 12 nonadjacent vines were selected as controls. Treatments consisted of control (water) and aqueous ethanol (5\% v/v) spray. Ethyl alcohol (USP 190 proof/95\%, AAPER Alcohol \& Chemical Co., Shelbyville, KY) was diluted with water and sprayed on each cluster of each treated vine to full coverage. Treatments were applied using a hand-held $3.79 \mathrm{~L}$ low-density polyethylene sprayer at a rate of 2 liters per vine, between 0800 and 1000 hr. Fruit sampling was conducted at weeks 14,15 , and 17 postbloom for Cabernet franc, and weeks 12, 13, and 16 postbloom for Merlot.

Cluster ethylene concentrations were determined by extraction of internal atmospheres from control and treated fruit, in triplicate, carried out 1, 3, 6, and $24 \mathrm{hr}$ postspray application. Immediately before analysis, clusters were harvested, adjusted to room temperature, washed with distilled water, weighed, and placed within a funnel, which was inverted and fitted with a $6.3 \mathrm{~mm}$ serum cap. The funnel, containing the grape cluster, was completely submerged in a $\mathrm{NaCl}$ solution $(0.36 \mathrm{~g} / \mathrm{L}$ granulated food grade salt in distilled water) inside a cylindrical pressure vessel $(30.5 \times 15.2 \mathrm{~cm})$ as described elsewhere (Maxie et al. 1965, Coombe and Hale 1973). A partial vacuum (686 mm Hg) was applied for $5 \mathrm{~min}$. The internal gases extracted from the fruit and collected from the top of the inverted funnel were sampled with a Hamilton (Reno, NV) Gastight model 1001 syringe for triplicate GC analysis of ethylene. Samples $(0.1 \mathrm{~mL})$ were injected directly into a Varian gas chromatograph (model 3740, Palo Alto, CA) $\left(10^{-2}\right.$ electron capture detector with positive output and an ion detector mode). Nitrogen gas flow rate was $30 \mathrm{~mL} / \mathrm{min}$, hydrogen was $30 \mathrm{~mL} / \mathrm{min}$, air was $300 \mathrm{~mL} / \mathrm{min}$, and a Supelco (Bellefonte, PA) 1\% SP-1000 on 60/80 Carbopack B packed column was used. Injection temperature was $150^{\circ} \mathrm{C}$, and column temperature $100^{\circ} \mathrm{C}$. 
Relative humidity was determined by digital hygrometer (Traceable, model 4187; Control Company, Friendswood, TX), and temperature by using an infrared thermometer (model 42529; Extech Instruments, Waltham, MA) within the vine canopy of control and ethanol-treated vines between 0800 and 1000 hr. At harvest, yield components were determined, including shoots per meter, clusters per shoot, clusters per vine, cluster weight, berry weight, berry numbers, and fruit weight per vine. Approximately $57 \mathrm{~kg}$ of Merlot fruit and 57 $\mathrm{kg}$ from each Cabernet franc canopy side were used for wine production.

Fruit and wine chemistry. Fifty berries per vine were randomly selected, weighed and crushed in $30.97 \mathrm{~cm}^{3}(15.24$ x 20.32 x $0.10 \mathrm{~cm}$ ) plastic sampling bags (Minigrip, Seguin, TX). Juice was filtered through $0.45 \mu \mathrm{m}$ syringe filters (Whatman, Clifton, NJ). Skins and juice were frozen at $-20^{\circ} \mathrm{C}$ for total glycosyl-glucose (TGG) and phenol-free glycosyl glucose (PFGG) analysis. Brix, $\mathrm{pH}$, and titratable acidity (TA) were analyzed, and color intensity $\left(\mathrm{A}_{420}+\mathrm{A}_{520}\right)$, hue $\left(\mathrm{A}_{420} / \mathrm{A}_{520}\right)$, and total phenols $\left(\mathrm{A}_{280}\right)$ were determined using a Genesys spectrophotometer (Spectronic, Leeds, UK), each as described previously (Zoecklein et al. 1999). Degrees Brix was measured by refractometer (model 10430; AO Scientific Instruments, Southbridge, MA).

The analyses of TGG and PFGG were performed as described (Williams et al. 1995) and modified (Zoecklein et al. 2000). L-Malic acid and yeast assimilable nitrogen (YAN) were determined enzymatically (R-Biopharm AG, Darmstadt, Germany, and Megazyme, Bray, Ireland, respectively), wine alcohol content by Fourier transform infrared (Foss WineScan FT 120, Eden Prairie, MN), and residual sugar concentration was estimated by Clinitest (Bayer, Pittsburgh, PA).

Wine samples for GC-MS analysis were prepared using a 4 $\mathrm{mL}$ sample with $\mathrm{NaCl}(1.0 \mathrm{~g})$ in $10 \mathrm{~mL}$ clear glass vials sealed with septa (MicroLiter Analytical Supplies, Suwanee, GA), as published elsewhere (Whiton and Zoecklein 2000). Vials were preincubated for $30 \mathrm{sec}$ at $30^{\circ} \mathrm{C}$ with agitation at $250 \mathrm{rpm}$. A CAR/DVB/PDMS grey SPME fiber (Supelco, Sigma-Aldrich, St. Louis, MO) was used to penetrate vials to a $32 \mathrm{~mm}$ depth into the headspace and was equilibrated for $30 \mathrm{~min}$. A GCMS system (model 6890N; Network GC System, 5975B inert MSD; Agilent Technologies, Santa Clara, CA) was used, with injector temperature at $250^{\circ} \mathrm{C}$, DB-Wax column $(30 \mathrm{~m} \mathrm{x} 0.25$ $\mathrm{mm}$ ), and helium carrier gas with a flow rate of $1 \mathrm{~mL} / \mathrm{min}$. Oven temperature was $40^{\circ} \mathrm{C}$ with a ramp rate of $6^{\circ} \mathrm{C} / \mathrm{min}$ to $230^{\circ} \mathrm{C}$. Thirty-two compounds were manually integrated and quantified using standard solutions.

Processing and fermentation. Cabernet franc and Merlot grapes were crushed and destemmed using a Wottle (Anton, Poysdorf, Austria) destemmer-crusher to $\sim 50 \%$ berry breakage, estimated visually. Berries were distributed into three open-top 60 L Nalgene fermenting bins of equal height and volume for each variety and treatment. Each bin was treated with $250 \mathrm{mg} / \mathrm{L}$ Velcorin (dimethyl-dicarbonate; Scott Laboratories, Petaluma, CA), followed by addition of $25 \mathrm{mg} / \mathrm{L}$ potassium metabisulfite. Grapes were cold soaked for six days at $7^{\circ} \mathrm{C}$, with daily punching of must caps.
Juice analysis was performed on day six of cold soak. Titratable acidity adjustments were made using tartaric acid, and YAN adjustments (12 g/100 L) using FermAid K (Lallemand, Blagnac Cedex, France). Go-Ferm (Lallemand) yeast nutrient was prepared according to manufacturer's recommendations and added during yeast rehydration. Saccharomyces cerevisiae ICV-D254 (Lallemand) yeast (24 g/100 L) was hydrated according to the manufacturer's recommendation and inoculated after cold soak. Caps were punched three times daily. Fermentation was monitored by hydrometry and carried out at $23 \pm 2{ }^{\circ} \mathrm{C}$ (liquid temperature) until dryness $(<1 \%$ residual sugar). Following fermentation, wines were dejuiced and pressed using a Willmes bladder press (model 100; Bensheim, Germany) to 0.5 bar. Free-run and press-run fractions were combined in sanitized glass carboys. Wine was kept at $7^{\circ} \mathrm{C}$ for $24 \mathrm{hr}$, then racked into carbon dioxide-filled $3.80 \mathrm{~L}$ glass bottles, and stored at $12^{\circ} \mathrm{C}$.

Electronic nose analysis. Two ENose systems were used: conducting polymer-based (CP) Cyranose 320 (Smiths Detection, Pasadena, CA) and surface acoustic wave-based (SAW) ZNose 7300 (Electronic Sensor Technology, Newbury Park, CA). The CP ENose optimization method for fruit (Athamneh et al. 2008) evaluated the impact of field variables, such as heat and humidity, in our climatic region. The wine optimization method for CP ENose was that of Gardner (2009). Optimizations involved evaluations of sample temperature, incubation time, pump speed, purge, and individual sensor response. Canonical projection plots showed no separations between replications, indicating minimum sensor drift. Optimum sample temperature was determined to be $30^{\circ} \mathrm{C}$. Ethanol standard solutions (three standards per treatment) were used to create an ethanol baseline to evaluate the impact on polymer sensor response and to minimize effects of differences in alcohol concentrations among wine samples while using the ENose. Concentrations for ethanol standards were based on the alcohol concentration of each wine treatment. For the SAW ENose, the default DB-5 system settings were used, except for the sensor temperature $\left(30^{\circ} \mathrm{C}\right)$. The system was calibrated using C6 to $\mathrm{C} 14$ alkane standards each day.

For field analysis, five ethanol-sprayed clusters per vine were randomly selected. Clusters were bagged with an HDPE bag (Interplast, Livingston, NJ) and equilibrated for $45 \mathrm{~min}$, followed by CP ENose evaluation of headspace volatiles. Fruit temperature, ambient temperature, and relative humidity were measured.

For laboratory analysis, five replicates of $20 \mathrm{~mL}$ juice or wine samples were placed in $40 \mathrm{~mL}$ GC clear glass vials sealed with Teflon/silicone $3 \mathrm{~mm}$ septa (MicroLiter Analytical Supplies, Suwanee, GA). ENose analysis of the samples occurred after equilibrating in a water bath at $30^{\circ} \mathrm{C}$ for 20 min. Wines were analyzed twice, once immediately postfermentation and again 6 months postfermentation.

Sensory analysis. A triangle difference test was conducted on wine aroma under standard conditions 6 months postfermentation, as described (Meilgaard et al. 2007), comparing control and ethanol treatments. Wines were prescreened for sulfurlike off odors. All wines were identified 
with a randomized three-digit code. Standard ISO glasses were filled with $20 \mathrm{~mL}$ wine and covered with petri dishes. Wines were presented to the panelists at $19 \pm 1.0^{\circ} \mathrm{C}$ under red light in separate booths in a controlled environment. Thirtytwo panelists aged 21 to 27 years, with a gender ratio of $1: 1$, were chosen $(\alpha=0.05, \beta=0.30, \rho d=40 \%, 16$ correct responses for significant difference), with a prerequisite of wine consumption at least once a week. Written instructions were provided and each panelist received two 20-min training sessions outlining the procedures. Each panel member smelled two sets of samples at different time periods.

Statistical analysis. The physicochemistry, CP, and SAW ENose data from grapes and wines were analyzed and compared using univariate (one-way analysis of variance, ANOVA), least significant difference (LSD), multivariate (canonical discriminate analysis, CDA) and principal component analysis (PCA) statistical methods using JMP software, version 7 (SAS Institute, Cary, NC). The SAW ENose data was analyzed using the GC chromatographic approach as described (Lammertyn et al. 2004). For the sensory data, the number of correct responses was counted.

\section{Results and Discussion}

Internal ethylene concentrations illustrated the impact of aqueous ethanol on ethylene production. Cabernet franc-1 (canopy east side) fruit demonstrated a pattern typical of this study. One-hour postspray, treated fruit had a mean ethylene concentration of $70 \mathrm{ppb}$, compared to $10 \mathrm{ppb}$ in control fruit. Three hours postspray, treated fruit averaged $50 \mathrm{ppb}$, while controls remained at $10 \mathrm{ppb}$. There were no differences between treatment and control Cabernet franc-1 fruit at 6- and 24-hr postspray, a consistent pattern for both cultivars.

Components of yield at harvest (shoots per meter, clusters per shoot, clusters per vine, cluster weight, berry weight, berry numbers, and fruit weight per vine) did not differ among control and ethanol treatment for either grape variety (data not shown). Fruit weight per vine averaged $3.1 \mathrm{~kg}$ and 2.47 $\mathrm{kg}$ for Cabernet franc-1 and -2 , respectively, and $5.27 \mathrm{~kg}$ for Merlot.
Physicochemical (Brix, berry weight, $\mathrm{pH}$, titratable acidity, color, total phenols, and total and phenol-free glycosides) differences between treatments for both varieties were determined (Table 1). Berry weights were not affected by treatment, consistent with results elsewhere (Chervin et al. 2001). Hue was the only Cabernet franc grape index that demonstrated a
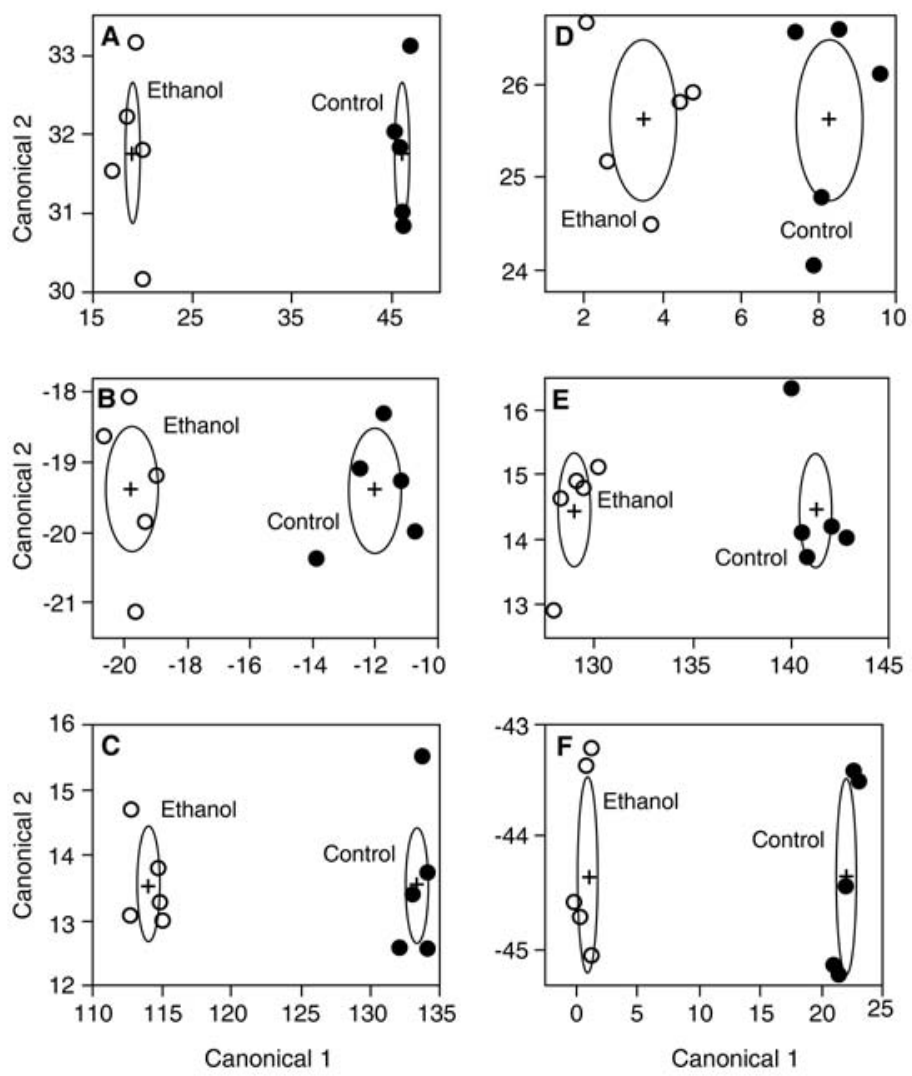

Figure 1 Canonical distribution of physicochemical analyses of ethanol treatment and control juice sampled at weeks (A) 14, (B) 15, and (C) 17 postbloom for Cabernet franc-1 (east-facing canopy side), and weeks (D) 14, (E) 15, and (F) 17 postbloom for Cabernet franc-2 (west-facing side). Significant differences at $\alpha=0.05$ level indicated by nonintersecting circles.

Table $1 p$ Values comparing physicochemical indices between ethanol treatment and control fruit, for three sampling periods for Cabernet franc-1 (east side of canopy), Cabernet franc-2 (west side) (weeks 14, 15, and 17 postbloom), and Merlot (weeks 12, 13, and 16 postbloom).

\begin{tabular}{|c|c|c|c|c|c|c|c|c|c|}
\hline \multirow{2}{*}{$\begin{array}{l}\text { Physicochemical } \\
\text { indices }\end{array}$} & \multicolumn{3}{|c|}{ Cabernet franc-1 } & \multicolumn{3}{|c|}{ Cabernet franc-2 } & \multicolumn{3}{|c|}{ Merlot } \\
\hline & Week 14 & Week 15 & Week 17 & Week 14 & Week 15 & Week 17 & Week 12 & Week 13 & Week 16 \\
\hline Brix & 0.79 & 0.81 & 0.22 & 0.97 & 0.69 & 0.27 & 0.72 & 0.86 & 0.19 \\
\hline Berry wt (g) & 0.24 & 0.31 & 0.94 & 0.71 & 0.10 & 0.08 & 0.71 & 0.95 & 0.63 \\
\hline $\mathrm{pH}$ & 0.96 & 0.62 & $0.00^{\star a}$ & 0.82 & 0.61 & $0.01^{*}$ & 0.80 & 0.93 & 0.44 \\
\hline Titratable acidity $(\mathrm{g} / \mathrm{L})$ & 0.20 & 0.14 & 0.12 & 0.26 & 0.48 & 0.41 & 0.27 & 0.78 & 0.70 \\
\hline $\begin{array}{l}\text { Color intensity } \\
\left(A_{420}+A_{520}\right)\end{array}$ & $0.05^{*}$ & 0.15 & 0.38 & $0.05^{*}$ & 0.15 & 0.11 & 0.66 & 0.79 & $0.05^{\star}$ \\
\hline Hue $\left(A_{420} / A_{520}\right)$ & 0.67 & $0.00^{*}$ & $0.03^{*}$ & $0.04^{*}$ & $0.00^{*}$ & $0.01^{*}$ & 0.88 & 0.77 & 0.28 \\
\hline Total phenols $\left(A_{280}\right)$ & $0.00^{*}$ & 0.08 & 0.71 & $0.03^{*}$ & $0.04^{*}$ & 0.34 & 0.07 & 0.21 & $0.01^{*}$ \\
\hline PFGG $(\mu M)$ & $n d^{b}$ & nd & 0.34 & nd & nd & $0.00^{*}$ & nd & nd & $0.03^{*}$ \\
\hline TGG $(\mu M)$ & nd & nd & 0.09 & nd & nd & 0.85 & nd & nd & 0.94 \\
\hline
\end{tabular}

${ }^{a}$ Asterisk indicates significant difference $(p<0.05)$.

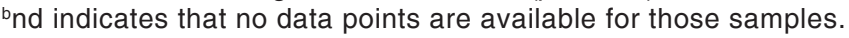


consistent pattern between ethanol-treated and control samples (five out of six sampling dates). Fruit $\mathrm{pH}$ values for both Cabernet franc plots demonstrated a treatment effect on the last sampling date. Color intensity differences have been reported as a result of ethanol treatment (El Kereamy et al. 2002). Treated Cabernet franc fruit did not consistently have higher color intensities. At harvest, Merlot ethanol-treated grapes did show a significant difference in color intensity. Phenol-free glycosides, which are, in part, aroma and flavor precursors, illustrated treatment differences for Merlot and for Cabernet franc-2 grapes at harvest.

Canonical discriminant analysis (CDA) of the seven physicochemistry indices (plus PFGG and TGG for the final harvest) explained $100 \%$ of the variation on all sampling dates, for Cabernet franc (Figure 1) and Merlot (Figure 2). The CDA plots represent the multivariate mean of the data points, with circles indicating the $95 \%$ confidence limit for the mean. Nonintersecting circles indicate significant differences. The CDA scores that validated the grouping of the classes indicated that all replicates of each treatment were identified correctly (data not shown).
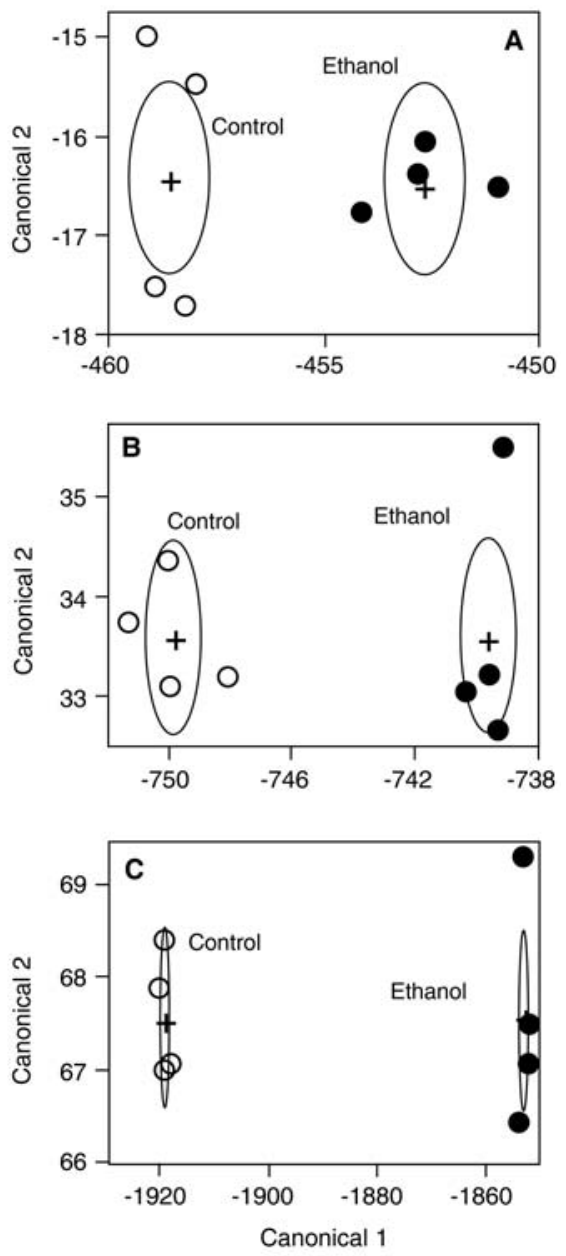

Figure 2 Canonical distribution of physicochemical analyses of control and ethanol treatment Merlot juice sampled at weeks (A) 12, (B) 13, and (C) 16 postbloom. Significant differences at $\alpha=0.05$ level indicated by nonintersecting circles.
Both the CP and SAW ENose systems were able to explain $100 \%$ of the variation with one qualitative/quantitative measurement of clusters (CP) and juice (CP and SAW) for Cabernet franc berries (Figure 3) and Merlot juice (Figure 4). Results for Cabernet franc-2 (west canopy side) showed similar separation (data not shown). From the CP-based system results, \#31 was the only sensor (identified by PCA vector plots) that did not help to explain the difference between control and ethanol treatments in both Cabernet franc and Merlot (data not shown).

Cabernet franc wine indices differed between treatment and control, with the exception of TGG and TA for both canopy sides and hue for Cabernet franc-2 (Table 2). Differences in wine alcohol and acidity for canopy sides reflect the differences noted in fruit maturity values. Those differences were also noted in the analysis of total phenols, color intensity, and phenol-free glycosides. Hue and total phenols were differentiated between treatments in Merlot wines (Table 2).

Canonical plots of Cabernet franc-1 (east canopy side) wines, using both $\mathrm{CP}$ and SAW ENose systems, demonstrated $100 \%$ difference between control and ethanol treatments (Figure 5A, B). These trends were the same for Cabernet franc-2 (data not shown). Merlot wines were also differentiated completely between control and ethanol treatments using both ENose systems (Figure 5C, D).
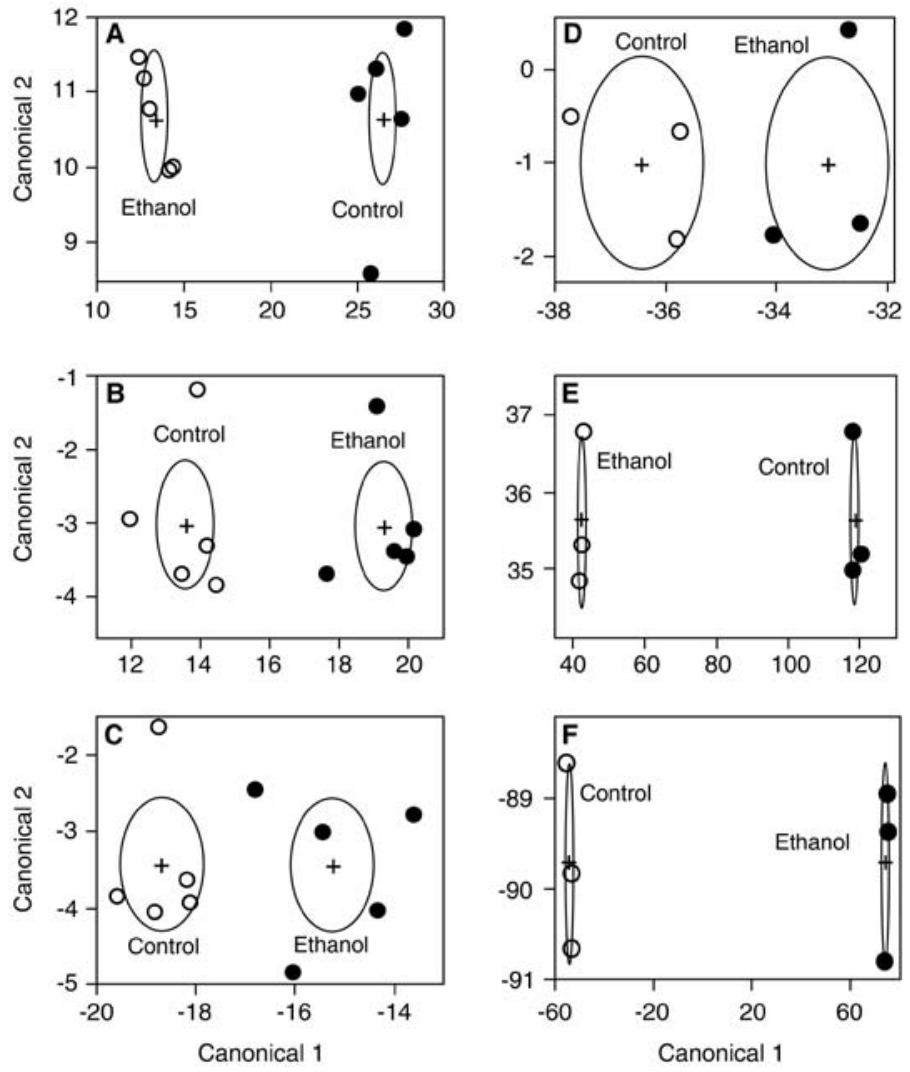

Figure 3 Canonical distribution of analyses of control and ethanol treatment Cabernet franc-1 (east-facing canopy side) berries using conducting polymer-based ENose at weeks (A) 14, (B) 15, and (C) 17 postbloom, and surface acoustic wave-based ENose at weeks (D) 14, (E) 15, and (F) 17 postbloom. Significant differences at $\alpha=0.05$ level indicated by nonintersecting circles. 
Table 2 Pairwise comparisons of control and ethanol treatment chemistry indices of Cabernet franc-1 (east side of canopy), Cabernet franc-2 (west side), and Merlot wines.

\begin{tabular}{|c|c|c|c|c|c|c|c|}
\hline Varietal/treatment & $\begin{array}{c}\text { Color intensity } \\
\left(A_{420}+A_{520}\right)\end{array}$ & $\begin{array}{c}\text { Hue } \\
\left(A_{420} / A_{520}\right)\end{array}$ & $\begin{array}{c}\text { Total phenols } \\
\left(A_{280}\right)\end{array}$ & $\begin{array}{c}\text { PFGG } \\
(\mu M)\end{array}$ & $\begin{array}{l}\text { TGG } \\
(\mu M)\end{array}$ & $\begin{array}{l}\text { Alcohol } \\
(\% \mathrm{v} / \mathrm{v})\end{array}$ & $\begin{array}{c}\text { Titratable } \\
\text { acidity }(\mathrm{g} / \mathrm{L})\end{array}$ \\
\hline \multicolumn{8}{|l|}{ Cabernet franc } \\
\hline Control-1 & $0.72 \pm 0.01 b^{a}$ & $0.47 \pm 0.01 b$ & $2.67 \pm 0.02 b$ & $28.18 \pm 3.71 b$ & $1388 \pm 33 a$ & $12.4 \pm 0.05 b$ & $3.74 \pm 0.10 a$ \\
\hline Ethanol-1 & $0.78 \pm 0.01 a$ & $0.50 \pm 0.01 a$ & $2.87 \pm 0.02 a$ & $62.68 \pm 3.71 a$ & $1498 \pm 33 a$ & $13.0 \pm 0.07 a$ & $3.49 \pm 0.10 a$ \\
\hline Control-2 & $0.52 \pm 0.02 b$ & $0.56 \pm 0.01 a$ & $2.45 \pm 0.03 b$ & $28.9 \pm 2.03 b$ & $1323 \pm 38 a$ & $12.5 \pm 0.09 b$ & $3.67 \pm 0.08 a$ \\
\hline Ethanol-2 & $0.72 \pm 0.02 a$ & $0.57 \pm 0.01 a$ & $3.02 \pm 0.03 a$ & $65.55 \pm 2.03 a$ & $1373 \pm 38 a$ & $13.2 \pm 0.07 a$ & $3.56 \pm 0.08 a$ \\
\hline \multicolumn{8}{|l|}{ Merlot } \\
\hline Control & $1.31 \pm 0.02 a$ & $0.43 \pm 0.01 b$ & $3.65 \pm 0.01 b$ & $89.99 \pm 4.62 a$ & $1963 \pm 54 a$ & $13.7 \pm 0.08 a$ & $4.90 \pm 0.06 a$ \\
\hline Ethanol & $1.29 \pm 0.02 a$ & $0.47 \pm 0.01 a$ & $3.81 \pm 0.01 a$ & $78.49 \pm 4.62 a$ & $1883 \pm 54 a$ & $13.8 \pm 0.10 a$ & $4.86 \pm 0.06 a$ \\
\hline
\end{tabular}

aWithin a varietal and canopy side, cells in each column marked by different letters indicate $95 \%$ significant difference.
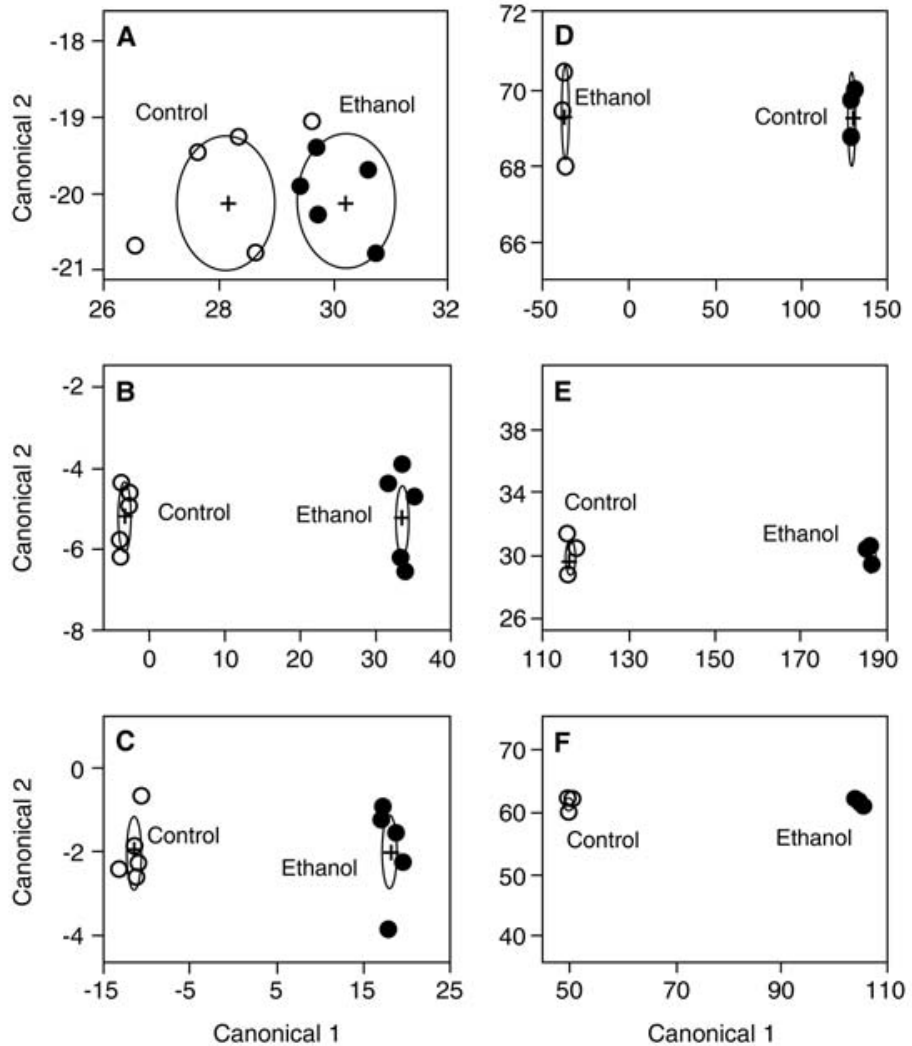

Figure 4 Canonical distribution of analyses of control and ethanol treatment Merlot juice using conducting polymer-based ENose at weeks (A) 12, (B) 13, and (C) 16 postbloom, and surface acoustic wave-based ENose at weeks (D) 12, (E) 13, and (F) 16 postbloom. Significant differences at $\alpha=0.05$ level indicated by nonintersecting circles.

The GC-MS wine analysis results, evaluated by ANOVA and pairwise comparison, showed the differences in volatile concentrations between ethanol treatment and control for both grape varietals (Table 3). In Cabernet franc-1 and -2, treatment and control wines showed differences in 26 of 31 volatiles quantified, perhaps consistent with the differences noted in fruit maturity and resultant alcohol concentration. Merlot wines demonstrated differences in 11 of 32 volatiles as a result of treatment, despite no differences in alcohol concentration between treated and control wines. As shown by CDA, GC-MS was able to $100 \%$ discriminate the ethanol
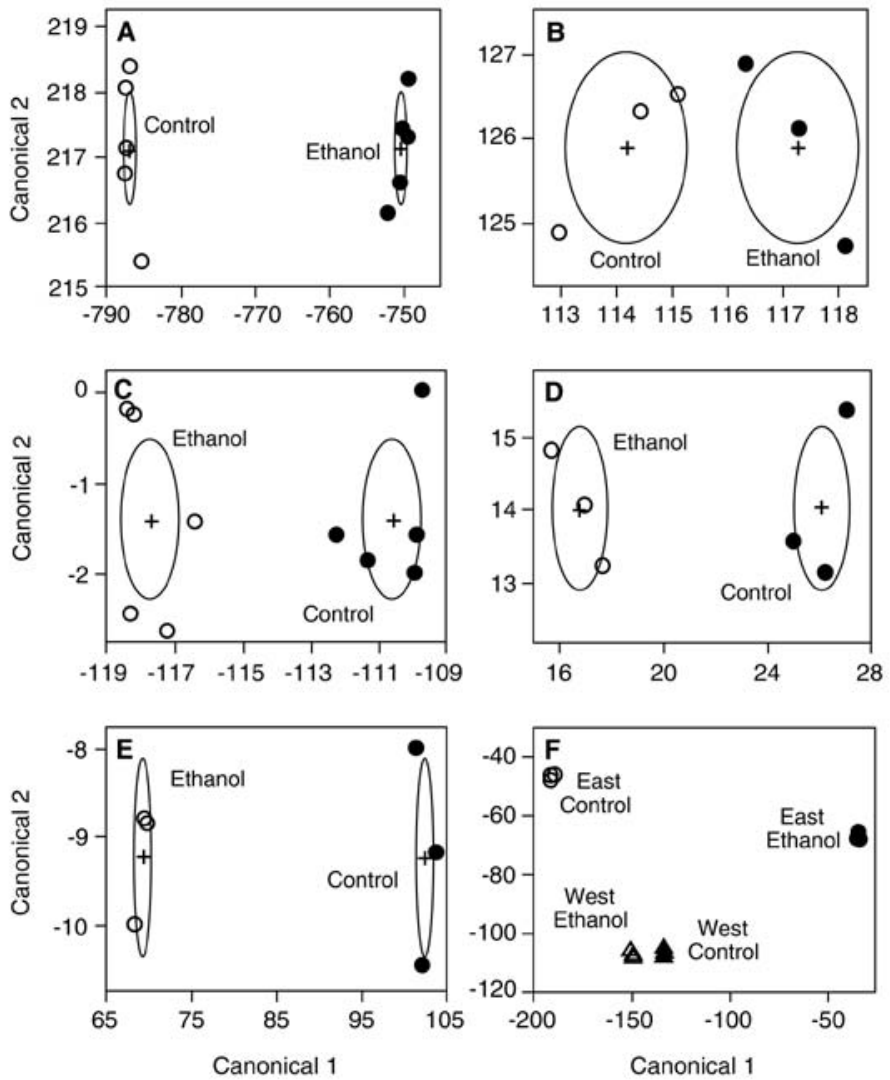

Figure 5 Canonical distribution of analyses of Cabernet franc-1 (eastfacing canopy side) wine using (A) conducting polymer-based (CP) and (B) surface acoustic wave-based (SAW) ENose, Merlot wine using (C) CP and (D) SAW ENose, and GC-MS analyses of control and ethanol treatment $(\mathbf{E})$ Merlot and $(\mathbf{F})$ Cabernet franc wines 6 months postfermentation. Significant differences at $\alpha=0.05$ level indicated by nonintersecting circles or groups of data.

treatment from control wines for both varietals (Figure 5E, F). The GC-MS data support the ENose results, which also showed differences between wines as a result of treatment.

Under the set conditions of the sensory evaluations $(\alpha=$ $0.05, \beta=0.30, \rho d=40 \%$ ), panelists were able to differentiate the ethanol-treated and control Merlot, but not the Cabernet franc wines (Table 4). Changing the test power by using an alpha level of 0.20 would result in significant differences for all sensory evaluations. The GC-MS data suggested significant 
Table 3 Effect of control and ethanol treatments on Cabernet franc-1 (east side of canopy) and -2 (west side) and Merlot wine volatiles as determined by GC-MS analysis.

\begin{tabular}{|c|c|c|c|c|c|c|c|c|}
\hline \multirow[b]{2}{*}{ Compound } & \multicolumn{5}{|c|}{ Cabernet franc concn $(\mu \mathrm{g} / \mathrm{L})$} & \multicolumn{3}{|c|}{ Merlot concn $(\mu \mathrm{g} / \mathrm{L})$} \\
\hline & Control-1 & Ethanol-1 & Control-2 & Ethanol-2 & $p$ value & Control & Ethanol & $p$ value \\
\hline Ethyl acetate & $24.88 \pm 0.34 b c^{a}$ & $25.71 \pm 0.34 a$ & $24.13 \pm 0.34 c$ & $29.13 \pm 0.34 a$ & $0.00^{* a}$ & $28.88 \pm 0.66 a$ & $30.28 \pm 0.66 a$ & 0.21 \\
\hline 1-Propanol & $n d^{b}$ & nd & nd & nd & $n a^{c}$ & $39.14 \pm 0.80 a$ & $38.53 \pm 0.80 a$ & 0.62 \\
\hline 2-Methyl propanol & $23.07 \pm 0.65 b c$ & $25.09 \pm 0.65 b$ & $22.44 \pm 0.65 c$ & $27.33 \pm 0.65 a$ & $0.00^{*}$ & $21.04 \pm 0.68 a$ & $20.83 \pm 0.68 a$ & 0.84 \\
\hline Isoamyl acetate & $3004.95 \pm 65.3 b$ & $3557.83 \pm 65.3 a$ & $2781.96 \pm 65.3 c$ & $3393.67 \pm 65.3 a$ & $.00^{*}$ & $5571.85 \pm 179.78 a$ & $5157.57 \pm 179.78 a$ & .18 \\
\hline$n$-Butanol & $9.12 \pm 0.01 c$ & $9.18 \pm 0.01 b$ & $9.13 \pm 0.01 c$ & $9.24 \pm 0.01 a$ & $0.00^{*}$ & $9.30 \pm 0.02 a$ & $9.34 \pm 0.02 a$ & 0.24 \\
\hline 3-Methyl butanol & $75.26 \pm 1.76 b c$ & $80.12 \pm 1.76 b$ & $71.77 \pm 1.76 c$ & $90.37 \pm 1.76 a$ & $0.00^{*}$ & $85.83 \pm 2.81 a$ & $86.62 \pm 2.81 \mathrm{a}$ & 0.85 \\
\hline Ethyl hexanoate & $216.73 \pm 4.29 b$ & $213.06 \pm 4.29 b$ & $194.05 \pm 4.29 \mathrm{c}$ & $246.09 \pm 4.29 a$ & $0.00^{*}$ & $342.71 \pm 10.09 a$ & $351.06 \pm 10.09 a$ & 0.59 \\
\hline Hexyl acetate & $4.17 \pm 0.07 a$ & $3.78 \pm 0.07 b$ & $1.47 \pm 0.07 d$ & $2.48 \pm 0.07 c$ & $0.00^{*}$ & $10.25 \pm 0.21 a$ & $6.82 \pm 0.21 b$ & $0.00^{*}$ \\
\hline Ethyl heptanoate & $5.01 \pm 0.10 c$ & $9.66 \pm 0.10 a$ & $5.05 \pm 0.10 c$ & $5.81 \pm 0.10 b$ & $0.00^{*}$ & $7.79 \pm 0.19 a$ & $8.38 \pm 0.19 a$ & 0.09 \\
\hline$n$-Hexanol & $1.54 \pm 0.04 b$ & $1.49 \pm 0.04 b$ & $1.69 \pm 0.04 a$ & $1.71 \pm 0.04 a$ & $0.01^{*}$ & $1.13 \pm 0.04 a$ & $1.02 \pm 0.04 a$ & 0.09 \\
\hline Ethyl octanoate & $109.93 \pm 2.06 \mathrm{c}$ & $117.37 \pm 2.06 b$ & $109.39 \pm 2.06 c$ & $155.68 \pm 2.06 a$ & $0.00^{*}$ & $168.08 \pm 3.07 a$ & $175.48 \pm 3.07 a$ & 0.16 \\
\hline 2-Ethyl-1-hexanol & $6.60 \pm 0.23 c$ & $9.60 \pm 0.23 a$ & $8.14 \pm 0.23 b$ & $9.59 \pm 0.23 a$ & $0.00^{*}$ & $5.98 \pm 0.22 b$ & $7.48 \pm 0.22 a$ & $0.01^{*}$ \\
\hline Benzaldehyde & nd & nd & nd & nd & na & $17.01 \pm 0.08 b$ & $18.73 \pm 0.08 a$ & $0.00^{*}$ \\
\hline Ethyl nonanoate & $24.13 \pm 0.04 c$ & $24.79 \pm 0.04 a$ & $24.29 \pm 0.04 b$ & $24.69 \pm 0.04 a$ & $0.00^{*}$ & $24.80 \pm 0.07 b$ & $25.41 \pm 0.07 a$ & $0.00^{*}$ \\
\hline 1-Octanol & $106.82 \pm 3.01 d$ & $129.47 \pm 3.01 c$ & $255.91 \pm 3.01 \mathrm{a}$ & $220.85 \pm 3.01 b$ & $0.00^{*}$ & $24.52 \pm 0.84 a$ & $26.11 \pm 0.84 a$ & 0.25 \\
\hline Terpinene-4-ol & $13.17 \pm 0.76 d$ & $27.37 \pm 0.76 c$ & $41.86 \pm 0.76 b$ & $50.93 \pm 0.76 a$ & $0.00^{*}$ & $2.11 \pm 0.05 b$ & $2.91 \pm 0.05 a$ & $0.00^{*}$ \\
\hline Ethyl decanoate & $70 c$ & $80.74 \pm 1.70 b$ & & $130.36 \pm 1.70 a$ & & $121.60 \pm$ & 113.14 & $0.03^{*}$ \\
\hline Isoamyl octanoate & $36.21 \pm 0.05 d$ & $36.80 \pm 0.05 b$ & $36.57 \pm 0.05 c$ & $37.46 \pm 0.05 a$ & $0.00^{*}$ & $38.71 \pm 0.05 a$ & $37.46 \pm 0.05 b$ & $0.00^{*}$ \\
\hline Nonanol & $7.92 \pm 0.25 b$ & $8.55 \pm 0.25 b$ & $12.01 \pm 0.25 a$ & $8.69 \pm 0.25 b$ & $0.00^{*}$ & $8.34 \pm 0.24 b$ & $9.31 \pm 0.24 a$ & $0.05^{*}$ \\
\hline Isovaleric acid & $2.23 \pm 0.05 b$ & $2.27 \pm 0.05 b$ & $2.05 \pm 0.05 c$ & $2.51 \pm 0.05 a$ & $0.00^{*}$ & $2.05 \pm 0.05 a$ & $2.12 \pm 0.05 a$ & 0.41 \\
\hline Diethyl succinate & $341.11 \pm 11.13 b$ & $369.07 \pm 11.13 b$ & $275.90 \pm 11.13 c$ & $515.46 \pm 11.13 a$ & $0.00^{*}$ & $264.11 \pm 7.97 a$ & $278.10 \pm 7.97 a$ & 0.28 \\
\hline Methionol & $1.56 \pm 0.04 a$ & $1.60 \pm 0.04 a$ & $1.57 \pm 0.04 a$ & $1.63 \pm 0.04 a$ & 0.59 & $2.05 \pm 0.12 a$ & $2.11 \pm 0.12 a$ & 0.78 \\
\hline Citronellol & $10.17 \pm 1.16 b$ & $10.28 \pm 1.16 b$ & $19.82 \pm 1.16 a$ & $22.74 \pm 1.16 a$ & $0.00^{*}$ & $3.81 \pm 1.25 a$ & $2.81 \pm 1.25 a$ & 0.60 \\
\hline Phenethyl acetate & $93.22 \pm 2.42 \mathrm{ab}$ & $98.47 \pm 2.42 a$ & $88.60 \pm 2.42 b$ & $89.15 \pm 2.42 b$ & 0.07 & $147.30 \pm 4.19 a$ & $119.46 \pm 4.19 b$ & $0.01^{*}$ \\
\hline$\beta$-Damascenone & $24.91 \pm 0.47 b$ & $22.61 \pm 0.47 c$ & $26.85 \pm 0.47 a$ & $17.84 \pm 0.47 d$ & $0.00^{*}$ & $6.39 \pm 0.20 a$ & $6.27 \pm 0.20 a$ & 0.71 \\
\hline Hexanoic acid & $1.04 \pm 0.05 a$ & $1.00 \pm 0.05 a$ & $0.98 \pm 0.05 a$ & $1.14 \pm 0.05 a$ & 0.22 & nd & nd & na \\
\hline Ethyl dodecanoate & $26.42 \pm 0.64 b$ & $27.84 \pm 0.64 b$ & $27.09 \pm 0.64 b$ & $39.78 \pm 0.64 a$ & $0.00^{*}$ & $54.89 \pm 0.76 a$ & $46.28 \pm 0.76 b$ & $0.00^{*}$ \\
\hline Benzyl alcohol & $137.62 \pm 2.87 \mathrm{c}$ & $149.97 \pm 2.87 b$ & $150.74 \pm 2.87 b$ & $166.07 \pm 2.87 a$ & $0.00^{*}$ & $176.51 \pm 5.27 a$ & $175.22 \pm 5.27 a$ & 0.87 \\
\hline Phenethyl alcohol & $21.12 \pm 0.63 b$ & $21.86 \pm 0.63 b$ & $20.96 \pm 0.63 b$ & $26.31 \pm 0.63 a$ & $0.00^{*}$ & $24.00 \pm 0.88 a$ & $25.37 \pm 0.88 a$ & 0.33 \\
\hline$\gamma$-Nonalactone & $0.08 \pm 0.00 b$ & $0.08 \pm 0.00 a b$ & $0.09 \pm 0.00 a$ & $0.09 \pm 0.00 a$ & $0.01^{*}$ & $0.06 \pm 0.00 a$ & $0.06 \pm 0.00 a$ & 0.37 \\
\hline Ethyl myristate & $41.18 \pm 0.16 a$ & $39.70 \pm 0.16 b$ & $40.02 \pm 0.16 b$ & $39.66 \pm 0.16 b$ & $0.00^{*}$ & $41.84 \pm 0.29 a$ & $41.22 \pm 0.29 a$ & 0.20 \\
\hline Octanoic acid & $1.63 \pm 0.14 a$ & $1.32 \pm 0.14 a$ & $1.63 \pm 0.14 a$ & $1.22 \pm 0.14 a$ & 0.16 & $2.08 \pm 0.16 a$ & $1.06 \pm 0.16 b$ & $0.01^{*}$ \\
\hline Ethyl palmitate & $89.01 \pm 0.53 a$ & $87.12 \pm 0.53 b$ & $87.61 \pm 0.53 a b$ & $89.05 \pm 0.53 a$ & 0.07 & $104.78 \pm 3.56 a$ & $111.72 \pm 3.56 a$ & 0.24 \\
\hline
\end{tabular}

aWithin a varietal, values in each row marked by different letters, and $p$ values with asterisks, indicate $95 \%$ significant difference.

bnd indicates that the volatile was not detected.

'na indicates that a $p$ value is not applicable for those samples.

Table 4 Triangle difference aroma sensory results of control versus ethanol spray $(\mathrm{EtOH})$ on Cabernet franc-1 (east side of canopy) and -2 (west side), and Merlot wines.

\begin{tabular}{lccc}
\hline Varietal/treatment & $\begin{array}{c}\text { Correct } \\
\text { responses }\end{array}$ & $\begin{array}{c}\text { Total } \\
\text { responses }\end{array}$ & Signifa $^{{ }^{2}}$ \\
\hline Cabernet franc & 9 & 32 & No \\
Control-1 vs EtOH-1 & 14 & 32 & No \\
$\quad \begin{array}{l}\text { Control-2 vs EtOH-2 } \\
\text { Merlot }\end{array}$ & 19 & 32 & Yes \\
Control vs EtOH & & & \\
\hline
\end{tabular}

${ }^{\mathrm{a}} \alpha=0.05, \beta=0.10, \rho_{\max }=40 \%, 16$ or more correct responses corresponds to a significant difference.

differences in some wine volatiles analyzed between treatments and control, indicating a treatment effect. The fact that ENoses can evaluate both aroma and nonaroma volatiles (Haugen and Kvaal 1998) may help to explain the variations between their discrimination abilities and some of the sensory evaluations. The sensory analyses were conducted using essentially untrained panelists. Evaluations using experienced, trained judges may have provided different results, as suggested elsewhere (Lattey et al. 2006).

\section{Conclusions}

Changes in grape and wine volatiles caused by spraying Cabernet franc and Merlot fruit with an ethanol/water solution at veraison were evaluated using conducting polymer-based and surface acoustic wave-based electronic nose systems. Both of the ENose systems were able to separate ethanoltreated grapes and wine from controls. Wine aroma sensory evaluation showed differences between treatments for Merlot only. Some individual physicochemistry indices did not show differences as a result of treatment for either variety. However, when all indices except TGG and PFGG were analyzed together (multivariate), ethanol treatments were distinguished from the controls $100 \%$ of the time. Although multivariate 
statistical results indicated the usefulness of traditional grape physicochemistry indices, the general inconsistency in detecting differences and the amount of time required to conduct these measurements suggests the need for alternatives. Electronic nose analysis (conducting polymer ENose) is a rapid and nondestructive technology that may supplement or replace the existing methods for evaluating select vineyard management practices. With only one measurement, the electronic noses demonstrated greater discrimination between ethanol-treated and control fruit and wines than did conventional assays.

\section{Literature Cited}

Athamneh, A.I., B.W. Zoecklein, and K. Mallikarjunan. 2008. Electronic nose evaluation of Cabernet Sauvignon fruit maturity. J. Wine Res. 19:69-80.

Barry, C., and J. Giovannoni. 2007. Ethylene and fruit ripening. J. Plant Growth Reg. 26:143-159.

Beaulieu, J.C., and M.E. Saltveit. 1997. Inhibition or promotion of tomato fruit ripening by acetaldehyde and ethanol is concentration dependent and varies with initial fruit maturity. J. Am. Soc. Hortic. Sci. 122:392-398.

Bergqvist, J., N. Dokoozlian, and N. Ebisuda. 2001. Sunlight exposure and temperature effects on berry growth and composition of Cabernet Sauvignon and Grenache in the Central San Joaquin Valley of California. Am. J. Enol. Vitic. 52:1-7.

Chervin, C., A. El Kereamy, J.P. Roustan, J.D. Faragher, A. Latche, J.C. Pech, and M. Bouzayen. 2001. An ethanol spray at véraison enhances colour in red wines. Aust. J. Grape Wine Res. 7:144-145.

Chervin, C., et al. 2004. Changes in grape maturity induced by spraying ethanol. Acta Hort. (ISHS) 640:305-311.

Coombe, B.G., and C.R. Hale. 1973. The hormone content of ripening grape berries and the effects of growth substance treatments. Plant Physiol. 51:629-634.

Devarajan, Y.S., B.W. Zoecklein, K. Mallikarjunan, and D.M. Gardner. 2011. Electronic nose evaluation of the effects of canopy side on Cabernet franc (Vitis vinifera L.) grape and wine volatiles. Am. J. Enol. Vitic. 62:73-80.

El Kereamy, A., C. Chervin, J.M. Souquet, M. Moutounet, M.C. Monje, F. Nepveu, H. Mondies, C.M. Ford, R. van Heeswijck, and J.P. Roustan. 2002. Ethanol triggers grape gene expression leading to anthocyanin accumulation during berry ripening. Plant Sci. 163:449-454.

Farag, K.M., J.P. Palta, and E.J. Stang. 1992. Ethanol enhances the effectiveness of ethephon on anthocyanin production in cranberry fruits in the field. HortScience 27:411-412.

Gardner, D.M. 2009. Characterization of cold soak on Vitis vinifera L. cv. Cabernet Sauvignon grape and wine volatiles using an electronic nose system. Master's thesis, Virginia Polytechnic Institute and State University, Blacksburg.

Gardner, D.M., B.W. Zoecklein, and K. Mallikarjunan. 2011. Electronic nose analysis of Cabernet Sauvignon (Vitis vinifera L.) grape and wine volatile differences during cold soak and postfermentation. Am. J. Enol. Vitic. 62:81-90.

Hale, C.R., B.G. Coombe, and J.S. Hawker. 1970. Effects of ethylene and 2-chloroethylphosphonic acid on the ripening of grapes. Plant Physiol. 45:620-623.

Haselgrove, D., D. Botting, R. van Heeswijck, P.B. Høj, P.R. Dry, C. Ford, and P.G. Iland. 2000. Canopy microclimate and berry composition: the effect of bunch exposure on the phenolic composition of Vitis vinifera L. cv. Shiraz grape berries. Aust. J. Grape Wine Res. 6:141-149.
Haugen, J.E., and K. Kvaal. 1998. Electronic nose and artificial neural network. Meat Sci. 49:S273-S286.

Hosel, W. 1981. Glycosylation and glycosidases. In The Biochemistry of Plants. Vol. 7. Secondary Plant Products. E.E. Conn (ed.), pp. 725-753. Academic Press, London.

Lammertyn, J., E.A. Veraverbeke, and J. Irudayaraj. 2004. zNose ${ }^{\mathrm{TM}}$ technology for the classification of honey based on rapid aroma profiling. Sens. Actuat. B: Chem. 98:54-62.

Lattey, K.A., B.R. Bramley, and I.L. Francis. 2006. Understanding consumer preferences of Shiraz and Cabernet Sauvignon wines. In Maximising the Value-Maximising Returns through Quality and Process Efficiency. M. Allen et al. (eds), pp. 7-10. Australian Society of Viticulture and Oenology, Adelaide.

Mallikarjunan, P. 2005. Electronic nose applications in the food industry. In Nondestructive Testing of Food Quality. J. Irudayaraj and C. Reh (eds.), pp. 237-284. Wiley-Blackwell, Ames, Iowa.

Maxie, E.C., N.F. Sommer, and D.S. Brown. 1965. Radiation technology in conjunction with post-harvest procedures as a means of extending the shelf life of fruit and vegetables: Annual report. U.S. Atomic Energy Commission, Division of Isotopes Development, Washington, DC.

Meilgaard, M.C., G.V. Civille, and B.T. Carr. 2007. Sensory Evaluation Techniques. 4th ed. CRC Press, Boca Raton, FL.

Pinheiro, C., C. Rodrigues, T. Schäfer, and J. Crespo. 2002. Monitoring the aroma production during wine-must fermentation with an electronic nose. Biotechnol. Bioeng. 77:632-640.

Powers, J.R., E.A. Shively, and C.W. Nagel. 1980. Effect of ethephon on color of Pinot noir fruit and wine. Am. J. Enol. Vitic. 31:203-205.

Ragazzo-Sanchez, J.A., P. Chalier, D. Chevalier, and C. Chommidh. 2006. Electronic nose discrimination of aroma compounds in alcoholised solutions. Sens. Actuators, B 114:665-673.

Roubelakis-Angelakis, K.A., and W.M. Kliewer. 1986. Effects of exogenous factors on phenylalanine ammonia-lyase activity and accumulation of anthocyanins and total phenolics in grape berries. Am. J. Enol. Vitic. 37:275-280.

Santos, J.P., J. Lozano, M. Aleixandre, I. Sayago, M.J. Fernandez, L. Ares, J. Gutierrez, and M.C. Horrillo. 2004. Discrimination of different aromatic compounds in water, ethanol and wine with a thin film sensor array. Sens. Actuators, B 103:98-103.

Shulman, Y., S. Cohen, and C. Loinger. 1985. Improved maturation and wine quality of Carignane grapes by ethephon treatments. Am. J. Enol. Vitic. 36:264-267.

Smart, R.E. 1985. Principles of grapevine canopy microclimate manipulation with implications for yield and quality. A review. Am. J. Enol. Vitic. 36:230-239.

Weaver, R.J., and R.M. Pool. 1971. Effect of (2-chloroethyl) phosphonic acid (ethephon) on maturation of Vitis vinifera L. J. Am. Soc. Hortic. Sci. 96:725-727.

Weaver, R.J., and I.S. Singh. 1978. Occurrence of endogenous ethylene and effect of plant regulators on ethylene production in the grapevine. Am. J. Enol. Vitic. 29:282-285.

Whiton, R.S., and B.W. Zoecklein. 2000. Optimization of headspace solid-phase microextraction for analysis of wine aroma compounds. Am. J. Enol. Vitic. 51:379-382.

Williams, P.J., W. Cynkar, I.L. Francis, J.D. Gray, P.G. Iland, and B.G. Coombe. 1995. Quantification of glycosides in grapes, juices, and wines through a determination of glycosyl glucose. J. Agric. Food Chem. 43:121-128.

Zoecklein, B.W., K.C. Fugelsang, B.H. Gump, and F.S. Nury. 1999. Wine analysis and production. Kluwer Academic Publishers, New York.

Zoecklein, B.W., L.S. Douglas, and Y.W. Jasinski. 2000. Evaluation of the phenol-free glycosyl-glucose determination. Am. J. Enol. Vitic. 51:420-423. 